\title{
Where You End and I Begin: Cognition and Continuity in Experimental Improvised Music and Dance
}

\section{Christopher Williams and Martin Sonderkamp}

Video:

Christopher Williams, contrabass

Martin Sonderkamp, dance

Thomas Martius, videographer

Before you are four excerpts of an hour-long studio session with Martin Sonderkamp and Christopher Williams, recorded and edited by videographer Thomas Martius in Berlin in February 2012. The performers are improvising artists by trade, and have collaborated on and off since 2007.

Before the session we had not performed together for over a year. During this hiatus, regular conversation often revolved around how the act of improvising brings us to think and feel through each other, as well as through our instruments and other factors in the performative environment. This conversation was initially inspired by Andy Clark and David Chalmers, Shaun Gallagher, Edwin Hutchins, Alva Noë, Lucy Suchman, and other cognitive scientists and philosophers of mind whose work foregrounds "the fact that cognition is a highly embodied or situated activity - emphasis intentionally on all three-and suggests that thinking beings ought therefore to be considered first and foremost as acting beings" (Anderson 91).

Of particular relevance was how these writers in their various ways "dissolve the traditional divisions between the inside/outside boundary of the individual and the culture/cognition distinction" (Rogers), for as practitioners we are constantly passing through these divisions and boundaries ourselves. Indeed, negotiating the fuzzy distinctions between us, our tools, and the environment is our bread and butter, as we ride the subtly coded movements of other musicians in an ensemble; find and use a fulcrum on another dancer's body; listen and adjust to room acoustics in real time; or evolve in tandem with an instrument's or a body's idiosyncrasies. In our experience as experimental improvisers, these continuities are especially significant, because they do not merely present-they are an explicit subject of investigation. By grounding performance in our changing surroundings and in each other, we give the cognitive network plasticity, we play with it, we open it up and invite the audience inside-a process of ongoing collective discovery.

The wide variety of case studies in research on embodied and situated cognition, from copy machine use ${ }^{1}$ to naval navigation ${ }^{2}$ has inspired us to reconsider how cognitive processes we tacitly know within a specific aesthetic framework (and attendant questions of form, material, affective meaning, etc.) are in fact at work throughout everyday life. The videos below reflect this reconsideration in action, and the accompanying texts attempt to open a few subjective windows thereto. We hope the performance and commentaries together provide you an occasion to explore these connections yourself firsthand.

\section{Where You End and I Begin: Video 1}

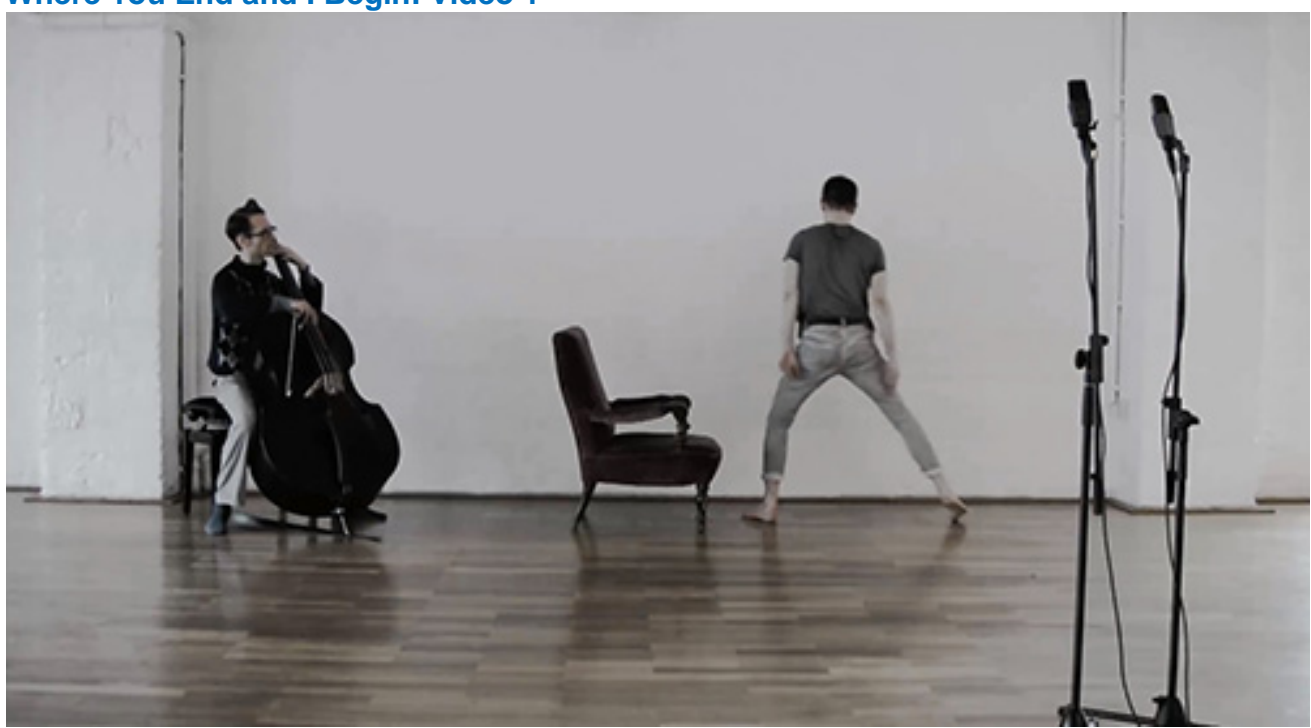


Observe how while sitting and playing the contrabass, Williams' musical thinking is coupled to the stool, the floor, his bow, and his instrument—not discrete agents, actors, and objects, but a complex sensing whole in which seemingly passive elements can have a direct role in shaping the musical discourse.

Take 1:15-2:00 for instance. Up until 1:15 in Part 1, Williams works on the strings of the instrument, focusing on subtle changes of left and right hand position in order to vary rhythmically, harmonically, and gesturally limited material. Then at 1:15, Williams' attention is drawn to the weight of the bow as it leaves the strings at the tail of an upward arpeggio, and he follows the kinetic momentum of his right arm. Exploring this sensation, he repeats the movement without actually sounding the strings. When he performs this gesture yet again at 1:20 (this time on the strings), his bow knocks against the side of the bass, introducing an unexpected foreign percussive element into the mix; his prosthesis has led him to new musical material.

He interrogates this discovery, now breaking up the gesture by rhythmically separating the causal movement of his bow and arm from the resultant clack on the wood of the instrument. The percussive sequence extends through his heel to the floor in a single phrase-whoosh-clack-stomp. The event brings the floor itself into Williams' musical field, and when he returns to the initial arpeggio gesture, he continues the movement by sliding the endpin (the "foot") of the bass along the ground. He instinctively holds onto the neck of the instrument to prevent it from falling, which changes his posture on the stool. This has unexpected structural consequences, for when the bass is recovered, Williams pivots on the stool ever so slightly in the direction of Sonderkamp, who by now has left the chair and engages Williams in a full-fledged duo.

Where You End and I Begin: Video 2

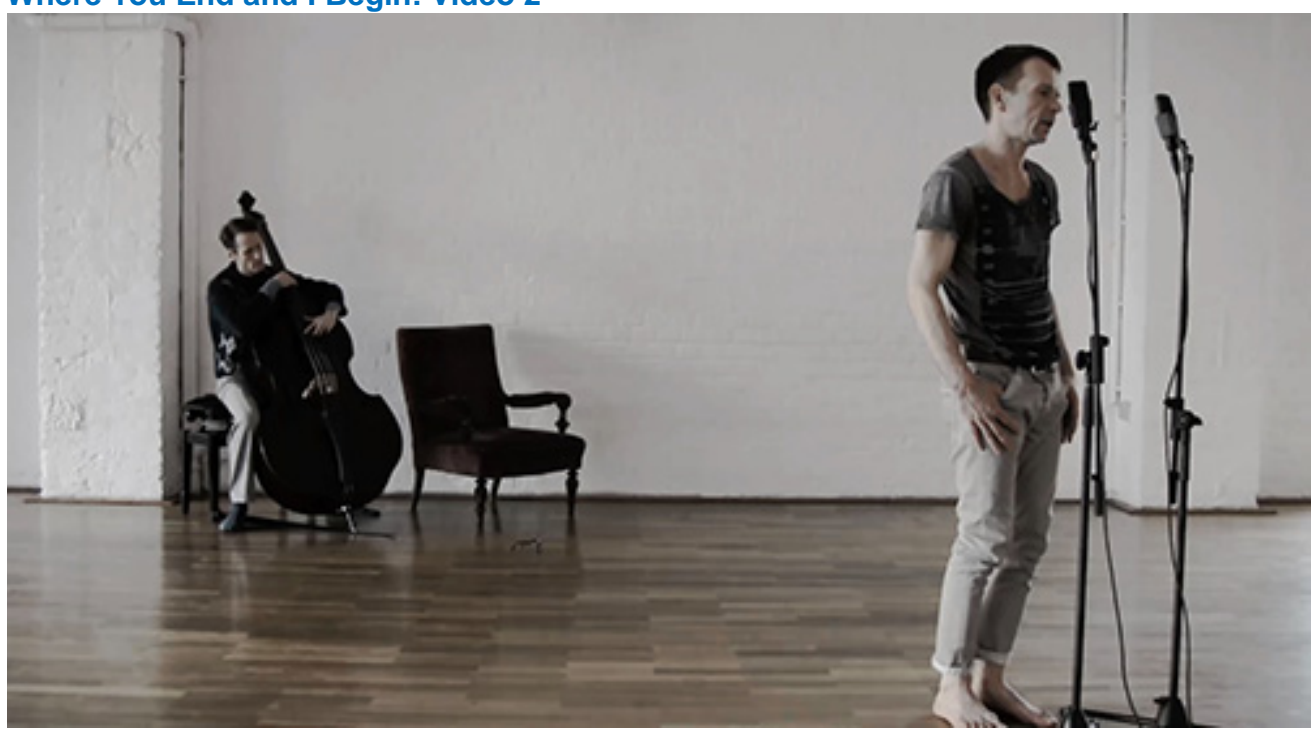

We

Analogous couplings are at work between Williams and Sonderkamp. We are not merely two individuals interacting, privately receiving inputs and outputs; we perceive and act simultaneously in a feedback loop with each other, relying intuitively on information which comes and goes faster than our ability to plan or hypothesize. We are thinking in movement and sound as parts of the same thinking-feeling-emoting entity.

Our continuity is evident in Part 2 as Sonderkamp imagines his ideal lover. Because of his position in the foreground of the video and audio recordings, Sonderkamp seems to lead the duet, telling a story while Williams plays along. However, from his location at the back of the room Williams cannot in fact comprehend Sonderkamp, who speaks into the microphones facing the opposite direction. Instead, Williams' meandering pizzicati dance with the rhythms and contours of Sonderkamp's speech, which reach Williams as muffled resonances in the reverberant studio. We constantly and unwittingly oscillate between initiation and response, as harmonic changes and percussive punctuations in the instrumental material in turn trigger thematic detours in the narrative, and alternations between first and third person.

This mutual dependence obtains additional significance around 2:20 when Sonderkamp's stream of consciousness begins to lose its tension, prompting Williams to get up and move across the room. A new part of the space opens up to Sonderkamp, who leaves the microphones, snoops around, and discovers Williams' bow on the stool along the way. While returning to his previous spot, Sonderkamp accidentally kicks Williams' glasses 
(which were invisible up to this point) across the floor, and they pop out of the background to become a subject in their own right. Our activity is arrested in a collective question mark: what were those glasses doing on the floor, and why aren't they on Williams' face? From 3:30 to 4:12 we slip down the rabbit hole together, collectively implicated in the task of working out, or through, this moment of confusion. Our mutual observation grows ever more intense. Distinctions between musician and dancer, sound and movement leak heavily as Sonderkamp bows the microphone, and Williams begins to exaggerate his head movements centre stage. As the show slows to a crawl, you can almost see and hear us thinking together.

\section{Where You End and I Begin: Video 3}

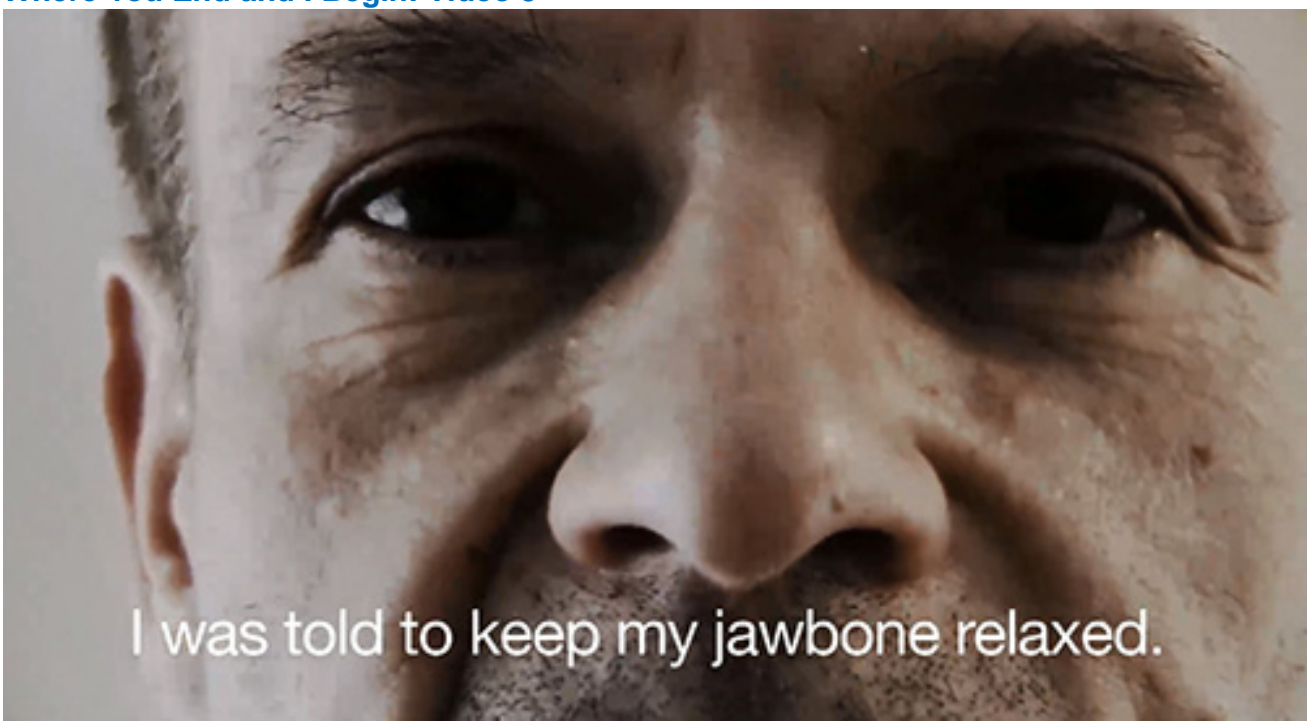

\section{You}

The sound of bow hair on metal microphone housing at the end of Part 2 projects through the virtual recording space into your ear. What sensation does that create, and what do you do with it? Are you together with us, feeling and acting through the video and loudspeakers (or headphones), as we are through our instruments, glasses, and floor? Are you making sense of your environment with us in Part 3 as your eyes meet Sonderkamp's, as your focus switches between the visual and auditory counterpoint of Williams' hands, or as you construct what's happening in the unseen corners of the room?

It is true that you, the performers, and the video are separated in time and space. But how significant is this gap, really? Is the cognitive loop necessarily limited to the dance studio, to the performers and videographer, to the moment of performance?

\section{Where You End and I Begin: Video 4}

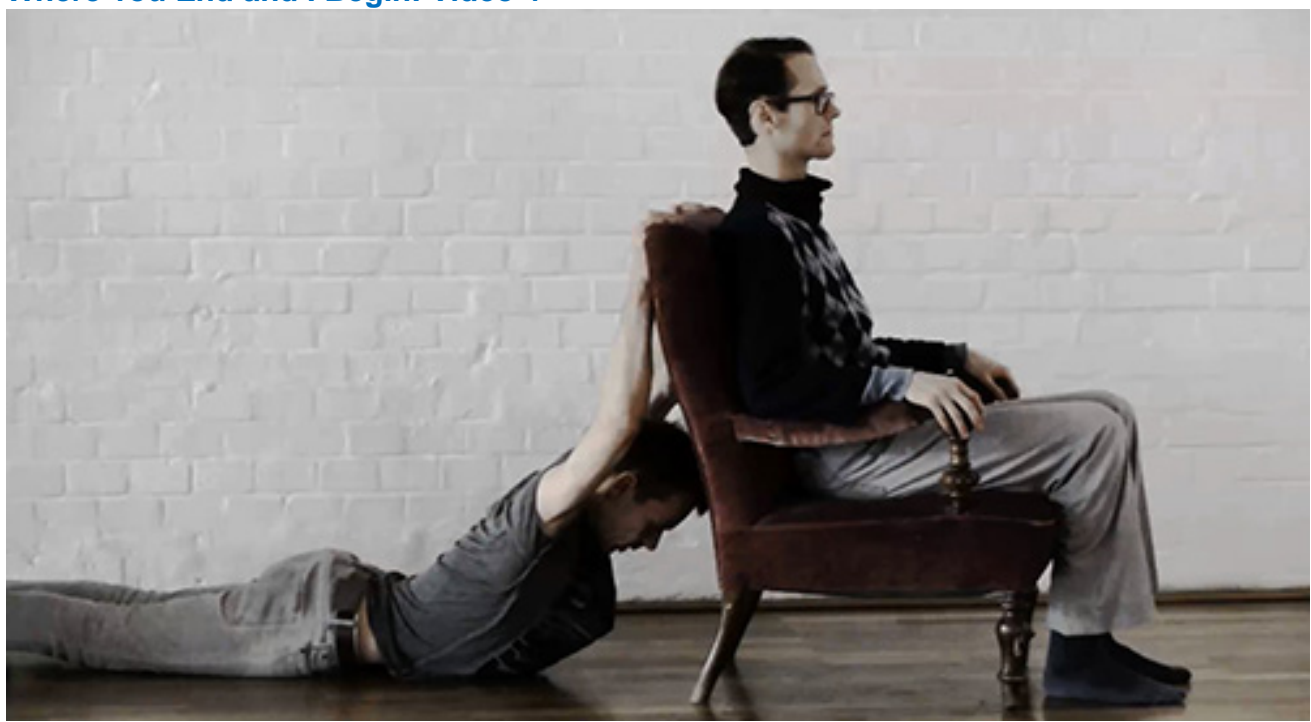


For us as performers, the event has passed. You can pause, fast forward, or rewind, even though the event itself is not repeatable. But take a closer look at how sense is transported over time from physical space to digital media onto the screen, through your eyes and ears into your body.

Martius's imagination of space and movement constitute the way you follow us. He composes an image within the frame of the camera and aligns this frame along the architecture of the room, giving a sense of both the space itself and of how our locomotion might be tied to it. As we move, this awareness extends medially to the viewer; his gaze moves the camera, the viewer's eye spontaneously follows, and one's attention is directed to details and events of which he becomes aware as he is filming.

At the same time we improvise with Martius's eyes as performers. We constantly feel the frontality of his gaze and its motion. Our actions depend on them-and on the awareness that someone else will be watching us. We are coupled to his way of viewing as much as you are.

We would like to end this text by suggesting a few ways to navigate this continuity yourself. Watch the videos again from the beginning. This time, play with the following options:

Video 1: Listen to the music with your eyes closed, paying close attention to the weight of your feet on the floor. How does the music feel through your ankles? The balls of your feet? Your toes?

Video 2: Open up a new Word document. With your hands on the computer keyboard, begin typing in unison with the movements of Williams' left and right hands. Copy the body of the text and paste it into the title of the file. Keep on hand for later use.

Video 3: Conjure up a description of your ideal lover, inserting bits into silences in the video. How does it change as Sonderkamp comes nearer?

Video 4: Stand up when there is no movement in the video. Take any movement as a signal to sit back down.

\section{An Interview between Chris Williams, Martin Sonderkamp, Amanda Ravetz, and Anne Douglas}

In July-September 2012 Williams and Sonderkamp were travelling and performing in Norway, Canada, Cologne, and Berlin. Special issue editors Ravetz and Douglas emailed Williams and Sonderkamp the following interview questions and this was their response.

Tell us about yourselves and your work with improvisation and each other. When did you start working together, how did you get into improvisation and why?

CW: Martin and I met in 2006 at a yoga class in Barcelona, where we were both living at the time. It turned out we had a colleague in common, Mary Oliver of Magpie Music and Dance Co. (of which Martin was a founding member). Martin invited me to accompany a workshop of his, and since then we have done several more workshops together, in addition to performing in ad hoc groups on occasion. Conversation about the connections between our practices has been ongoing, and recently this has centered on our mutual interest in embodied and situated cognition.

How did I personally get into improvisation? When I was twelve, I wanted to play with my next-door neighbor in a heavy metal band. He already played guitar, drums weren't my cup of tea, and electric bass was the only other instrument I could think of! This is what you might call improvisation as a (dynamic) fact of life. My interest in improvisation as a concept, a discipline, a tradition, came a few years later after starting to play the contrabass, which I took up because of my interest in jazz. My imagination didn't really fit into the typical role of a jazz bassist though, and I began to gravitate more toward free jazz and experimental music. Challenging and open-minded teachers fed the fire, especially my mentor Bert Turetzky, and since then improvisation has been an essential part of what I do.

MS: How did I get into improvisation? By playing, and learning as a child. I guess I was an expert then. I used to play in three different volleyball teams simultaneously and that's how I learned about improvising with others.

My first improvised dance performance happened 1991 in Accra, Ghana, when as a drummer I was gently forced to dance during a ritual ceremony in front of a large crowd. Since then improvisation has been at the center of my artistic practice, and I have studied with Steve Paxton, Katy Duck, Simone Forti, J. Hamilton, David Zambrano, 
and at the SNDO in Amsterdam. My affinities as an artist are towards play, research, and experiment. As a performer, I prefer the mindsets and sensory modes that occur while improvising to the ones that occur when I perform set work.

Somatic practices like Alexander Technique, BMC, Klein technique, Bartenieff, and yoga have informed my way of working with the body in training, performance, and artistic research. These fields are directly intertwined with my improvisatory practice. At the same time, my readings in the fields of embodied cognition and neuroscience have been intertwined with my artistic practice over the last four years. The writings of Ramachandran and Gallagher in particular have inspired a series of artistic labs in which I transposed terminologies and methods from the fields of cognitive science and neuroscience into my artistic practice and devised improvisatory tools (patches) that employ concepts such as "as-if" body loops, consciously non-intended movement, empathy, and extended body image.

\section{Is there a difference between improvisation as a dancer and as a musician?}

MS: We enact the same situation and perceive similar sense data but we process different parameters. We use different tools to produce different material through which we affect our environment. A musician's perception of the dancer's actions is often through his eyes; the dancer sees and can hear the musician.

Besides these obvious differences, a dancer perceives and acts through one instrument, the body, whereas a musician perceives and acts with two instruments-a body and a musical instrument. As a dancer I feel my own movement and its feedback on the structure of my body most strongly, but a musician is probably more attuned to how I work with the permeability of my body in space, or how different body-images affect intentionality.

On the other hand, there are many subtle points of continuity. Sound permeates the body twofold, not only via the eardrum, but also as vibration of the flesh. Music is thus a very intimate partner to work with. Likewise, the musician receives not only acoustic feedback from the instrument, but also has a spatial awareness (i.e. moving the bow), to which I as a dancer am naturally very sensitive. So I think we often start with a perceptual loophole.

There is a crossover of your roles in this piece (where for example Christopher uses movement and Martin uses the bow and his voice) that seems to raise questions of expertise. What do these reversals do within the piece?

MS: I think what these reversals do is that they open up situations, where we negotiate our play in such a way that we can agree to share parameters, where we also agree on similar tactics through empathy, imitation, and touch. The reversals regenerate playfulness in rehearsal and fuel excitement because of potential failure. They subvert our cultivated ways of doing things and make us more alert. Instability sharpens our senses. The reversals also cause a certain sense of complicity, sometimes foolishness. Ultimately they open up a pathway for collaboration.

Improvisation is often articulated as a tension between freedom and constraint-does that speak to your experience? If not, what other articulation about improvisation would you offer?

CW: Certainly the freedom-constraint dialectic has its place in the world, but we tend not to dwell on it. Personally, it brings up all kinds of associations that make me cringe: the Jamey Aebersold brand of jazz education, Pierre Boulez's moralizing about compositional technique, certain Americans' aversion to public health care-admittedly these are banal examples, and the idea has a rich philosophical history that I am lamentably unequipped to address here, but perhaps in our work, improvisation is better characterized simply as a quality of experience.

MS: Sure there is freedom and constraint, but in our collaboration it plays a minor role. We stress our mutual play, the way we build structures, the way we play alone or together, the way we alternate function, tools, genres-

CW: Playfulness, connection with one's surroundings, and sensorial depth are of course not unique to improvised music and dance. These qualities of experience are in fact available in all music, and in every aspect of our lives, even when we are not aware of it. For this reason we prefer concepts like feedback, unfolding activity, etc.; we want to emphasize the mutual dependency between us, our tools, our space, and you as an observer, which goes deeper than genre, aesthetics, or the creative act. This would seem to defuse the kinds of causal relationships (between environment and perception, of thought and action, of my glissando to Martin's leap) and willfulness that the freedom-constraint model suggests to me.

How or what did you agree in advance of making this piece?

CW: The decisions made before playing were almost entirely practical. Martin and I were invited to present at the 
conference in Delhi, ${ }^{3}$ which gave rise to this publication, and because of timing and funding issues it was decided I should go alone. Since a duo performance was not possible and a telematic performance seemed technically risky, we settled on presenting a video of our work. Scheduling limited us to a three-hour block in the studio to record; subtracting setup, warm up, and packing left us one hour to play. From this footage we would cherry-pick the moments that best "argued" the ideas addressed in our presentation text.

MS: We agreed not to rehearse beforehand, and that we would not work with a script. We agreed to treat this session with the same seriousness and intention we usually have towards performing in public. The video was to be mostly a registration and the camera would not be moved or touched by Christopher or me. We would accept the simple, current light conditions and work within the limits of the radius of visibility on screen. Then of course we had a time limit and worked with that sense of time. Also, having the microphones allowed for working with text and music.

CW: What's fascinating for me in retrospect is how certain conditions or parameters which seemed initially arbitrary enter our feedback loop and become significant "players" in the discourse of the improvisation. The microphone placement-which was decided at the last minute-is a clear example. The armchair also profoundly shapes our sense of space and how we move together. It's not merely a prop, or even an object per se. It's engaged in a process of transformation with us; at first it's a bed, then a balance beam, then a noise-maker, and at the end it becomes a kind of flying carpet. This phenomenon in a more general sense happens all the time in improvisation, and is probably one of the universal appeals of improvising.

\section{Do you agree that in this piece the videographer could also be thought of as a third improviser?}

MS: Yes, of course the videographer is a fellow improviser. Thomas's presence and the presence of the camera cannot help having influenced our decision-making during the course of the session. Take, for instance, Video 3. Knowing the perspective of the camera, I begin the section by composing an image with my arms outstretched as if they belonged to Christopher. Thomas responds in real time to the composition by moving the camera so that my arms are aligned to the lower part of the frame. When Christopher moves upstage, Thomas switches camera, zooming out on the whole space. As I move back into the foreground, he centers the camera on me, egging me on toward him. This relationship takes on another dimension when I begin staring through the camera at him, and on through to the viewer. Such a sequence would not have happened without an active and alert videographer such as Thomas participating in the process with us.

What has been the value of research to your exploration and experimentation?

CW: Research, exploration, and experimentation are one big knot for me. For example, my current PhD project, on the subject of notation for improvisers since 1960, involves conventional research-reading and writing, collecting and analyzing data-but even the most theoretical elements are grounded in practice. This is primarily out of necessity, because the music l'm looking at (both mine and others') is so resistant to existing theoretical or historical models in the field. So an important part of my research is playing these pieces, or playing with them by working out alternative versions, making speculative transcriptions, and so on. I learn things about this music through hands-on experimentation that I could never imagine through theory or analysis alone.

Recently, Martin and I have been developing a score with a group of Norwegian dancers based on hybrid notations that can be used by both dancers and musicians. In order to get a better sense of how these dancers relate to notation, we organized a week-long work session to which I brought some rule-based and/ or graphic scores by Malcolm Goldstein, Werner Dafeldecker, Kenneth Gaburo, and John Cage that I thought would resonate with them. We learned a lot of surprising stuff! The meanings of gesture, of physical presence, of different ways to structure transitions between subsets of an improvising ensemble are very important to these scores, but I had been only obliquely aware of this fact before really getting my hands dirty.

MS: My current research is mainly in the areas of performative practices, improvisation, and dramaturgy. These areas are inspired by the writings of Gallagher, Noë, Blakeslee and Ramachandran, and Massumi, which have provided me a different outlook on my own artistic practice outside of my own artistic parameters. Currently, I am developing choreographic methods that highlight the unintentional. The method is based on the use of small clusters of tasks and rules, called patches, that serve as recycling loops through which we interpret other dancers' material. Each patch triggers distinct perceptual modes, which are coupled to choreographic tasks. These were closely integrated into the sessions Christopher describes.

CW: Our ability to make sense of these scores was very much informed by the embodied and situated cognition literature discussed above. This research provides not only useful models to describe what's happening in improvisation from an observer's perspective, but they also provide an incredibly rich, and for me inspiring, way to focus many basic practical questions for performers. In particular, Edwin Hutchins's description of naval navigation in Cognition in the Wild helped me to explain to the dancers how Werner Dafeldecker's Mirror score sets up quartet (global) structures whose success depends on a series of (local) duos. An ironic connection to be 
sure, but a useful one all the same!

\section{Notes}

${ }^{1}$ See Suchman's Human Machine Reconfigurations (2007).

2 See Hutchins's Cognition in the Wild (1995).

3 The conference of the Association of Social Anthropologists of the UK and Commonwealth held at Jawaharlal Nehru University, New Delhi, India, 3-6 April 2012 on the topic of Art and Aesthetics in a Globalising World.

\section{Works Cited}

Anderson, Michael L. “Embodied Cognition: A Field Guide." Artificial Intelligence 149 (2003): 91-130. Print.

Blakeslee, Sandra and V.S. Ramachandran. Phantoms in the Brain: Probing the Mysteries of the Human Mind. New York: Harper Collins, 1999. Print.

Clark, Andy and David Chalmers. "The Extended Mind." Analysis 58 (1998): 10-23. Print.

Gallagher, Shaun. How the Body Shapes the Mind. Oxford: Oxford UP, 2005. Print.

Gallagher, Shaun and Dan Zahavi. The Phenomenological Mind. London: Routledge, 2007. Print.

Hutchins, Edwin. Cognition in the Wild. Cambridge, MA: MIT Press, 1995. Print.

Massumi, Brian. Parables for the Virtual: Movement, Affect, Sensation. Durham: Duke UP, 2002. Print.

Noë, A. Action in Perception. Cambridge, MA: MIT Press, 2004. Print.

Rogers, Yvonne. "A Brief Introduction to Distributed Cognition." The Open University. Web. 26 Apr. 2011. http://mcs.open.ac.uk/yr258/publications.html

Suchman, Lucy. Human-Machine Reconfigurations: Plans and Situated Actions. $2^{\text {nd }}$ ed. New York: Cambridge UP, 2007. Print. 